\title{
Wolbachia and cytoplasmic incompatibility in the spider mites Tetranychus urticae and $T$. turkestani
}

\author{
JOHANNES A. J. BREEUWER* \\ Institute for Systematics and Population Biology, University of Amsterdam Kruis/aan 320, 1098 SM Amsterdam, The \\ Netherlands
}

\begin{abstract}
Wolbachia form a group of closely related intracellular Proteobacteria that manipulate reproduction of their arthropod host in various ways. They are widespread in insects, but have not been not looked for in other arthropods except a few isopods and a predatory mite. Recently, Wolbachia were demonstrated to be widespread in mites also. Here, I report that Wolbachia induce cytoplasmic incompatibility in two spider mite species, Tetranychus urticae and T. turkestani, in crosses between infected and uninfected individuals. Uninfected mites were derived from the infected lineage by antibiotic treatment. Similar to other examples of cytoplasmic incompatibility, subsequent crosses between uninfected (cured) female and infected male spider mites were different from all other cross combinations. This suggests that the dynamics and evolution in Wolbachia-mite relationships may share many features with the Wolbachiainsect systems. Interestingly, the incompatible cross showed high $F_{1}$ zygotic mortality among females, but not among males. This zygotic mortality in the haplodiploid spider mites was in sharp contrast to the phenotypic effects of cytoplasmic incompatibility reported previously in haplodiploid insects. In the latter, cytoplasmic incompatibility results in all male or male-biased offspring because of haploidization of the fertilized egg with little or no zygotic mortality. Possible explanations are low bacterial densities and the different, holokinetic chromosome structure in spider mites.
\end{abstract}

Keywords: chromosome behaviour, cytoplasmic incompatibility, embryo mortality, spider mite, Tetranychus, Wolbachia.

\section{Introduction}

Wolbachia are a group of closely related intracellular bacteria that manipulate the reproduction of their arthropod host in various ways which promote their spread through the host population. Wolbachia are typically localized in the reproductive tissues of arthropods and are maternally transmitted through the egg cytoplasm. So far, Wolbachia have been implicated as the causative agent of postzygotic reproductive incompatibility (or cytoplasmic incompatibility) in many insect species and an isopod (see Breeuwer et al., 1992; O'Neill et al., 1992; Rousset et al., 1992), parthenogenesis in parasitic wasps (Stouthamer et al., 1993), and feminizing genetic males in isopods (Rigaud et al., 1991). In a few cases Wolbachia do not have an effect on host reproduction (Giordano et al., 1995; Turelli \& Hoffmann 1995).

*E-mail: breeuwer@bio.uva.nl
Finally, many more insect hosts are known to harbour Wolbachia, but their effect on host reproduction has not been determined (O'Neill et al., 1992; Rousset et al., 1992; Werren et al., 1995a,b). They are widespread in insects, occurring in 15 per cent of species examined (O'Neill et al., 1992; Werren et al., 1995a,b), but outside the insects they have only been reported in a few isopods (Rousset $e t$ al., 1992). Recently, Breeuwer \& Jacobs (1996) established that Wolbachia are widespread in spider and predatory mites, but their effects on mite reproduction have not been studied.

Wolbachia exploit two routes to increase in frequency (proportion of infected hosts): (i) conversion of genetic males into phenotypic, functional females as in a number of isopods or female parthenogenesis (thelytoky) in several parasitoid wasps. Everything else being equal, this will directly increase the frequency of the Wolbachia-transmitting sex, the females, in the host population; (ii) reducing 
or preventing production of uninfected offspring. This phenomenon is called cytoplasmic incompatibility and results in zygotic mortality in diploid species (Laven, 1967; Hoffmann \& Turelli, 1988; O’Neill \& Karr, 1990) and male-biased or all-male offspring in haplodiploid, hymenopteran species (Richardson et al., 1987; Breeuwer \& Werren, 1990).

Cytoplasmic incompatibility is typically observed in crosses between males infected with Wolbachia and uninfected females, and results in a reduced number of surviving hybrid offspring, relative to all other, compatible, crossing combinations between infected and uninfected individuals. This phenomenon was first discovered in Culex mosquitoes (see Laven, 1967) in which certain crosses resulted in complete or partial embryonic death of offspring. Currently, cytoplasmic incompatibility caused by intracellular bacteria has been demonstrated in a large number of different insect species (see Breeuwer et al., 1992; O'Neill et al., 1992; Rousset et al., 1992; Werren et al., 1995b) and an isopod (Rousset et al., 1992).

The precise mechanism of cytoplasmic incompatibility is not known. In the parasitic wasp Nasonia, cytoplasmic incompatibility results in improper condensation and fragmentation of the paternal chromosomes in the first mitotic division of the fertilized egg (Ryan \& Saul, 1968; Breeuwer \& Werren, 1990; Reed \& Werren, 1995). Similar abnormal mitosis has been observed in Drosophila simulans (O'Neill \& Karr, 1990; Callaini et al., 1994) and Culex pipiens (Jost, 1970), indicating that the same mechanism may be operating in diverse species. Apparently, paternal chromosome loss restores the haploid status of fertilized eggs in haplodiploid Hymenoptera, because they develop into normal males. In diploids, chromosome loss results in aberrant development eventually leading to embryonic death. Thus, male-biased sex ratios and/or high zygotic mortality, may be an indication that Wolbachia are involved. Such incompatibilities have been reported in both spider mites and predatory mites.

In spider mites as well as in predatory mites, there are several reports on embryo mortality and malebiased sex ratios of $F_{1}$ offspring in crosses between populations in several species, such as Tetranychus urticae (de Boer \& Veerman, 1983; Young et al., 1985; Gotoh et al., 1993), T. neocaledonicus (Gutierrez \& van Zon, 1973), the T. telarius-bimaculatus complex (Dillon, 1958), T. quercivorus (Gotoh et al., 1995), Panonychus ulmi (Gotoh \& Noguchi, 1990) and P. citri (Osakabe, 1993). Intracellular microorganisms have been demonstrated cytologically in the spider mite T. urticae (Sologic \& Rodriguez, 1971). Recently, Tsagkarakou et al. (1996) molecularly identified Wolbachia in a strain of T. urticae based on $f t s Z$ and $16 \mathrm{~S}$ ribosomal DNA sequence analysis. In predatory mites, Hoy \& Cave (1988) observed nonreciprocal $F_{1}$ mortality and male-biased sex ratios among populations of the phytoseiid predatory mite Metaseiulus occidentalis. They suggested the possibility that unidirectional incompatibility might be mediated by microorganisms similar to those found in insects showing cytoplasmic incompatibility, based on earlier observations of rickettsialike microorganisms in this species (Hess \& Hoy, 1982). Recently, Johanowicz \& Hoy (1996) confirmed the presence of Wolbachia in $M$. occidentalis based on the similarity of $16 \mathrm{~S}$ ribosomal DNA sequences.

To demonstrate that reproductive incompatibility is caused by microorganisms, Werren \& Jaenike (1995) suggested the following procedure based on Koch's postulates: (i) showing the presence of microorganisms in reproductive tissues; (ii) eliminating these microorganisms from the infected strain or species by antibiotic treatment; and (iii) showing cytoplasmic incompatibility in crosses between infected and cured strains. Although the presence of Wolbachia has been demonstrated in a number of mite species, it is unclear whether they can induce cytoplasmic incompatibility in mites (Breeuwer \& Jacobs, 1996; Johanowicz \& Hoy, 1996; Tsagkarakou et al., 1996). Here I report on Wolbachia in two species of spider mites, Tetranychus urticae and $T$. turkestani, that cause unidirectional cytoplasmic incompatibility between infected and uninfected spider mites.

\section{Materials and methods}

\section{Mite species}

The spider mite $T$. urticae was originally collected from tomato plants in a greenhouse in Naaldwijk, The Netherlands in 1992. This is the same strain that has been extensively studied by Gotoh et al. (1993) with respect to host race formation and reproductive incompatibility with a $T$. urticae strain collected from cucumbers in a greenhouse in Wageningen, The Netherlands. Tetranychus turkestani was collected from banana fruits in a grocery store in Amsterdam, The Netherlands in 1993. In the laboratory, spider mites have since been raised on detached leaves of the common bean, Phaseolus vulgaris, in controlled environment rooms $\left(23^{\circ} \mathrm{C}\right.$, $\mathrm{LD}=16: 8$, RH $60-60$ per cent). Both strains are 
infected with Wolbachia based on a PCR assay described below (Breeuwer \& Jacobs, 1996).

\section{PCR assay for Wolbachia}

Wolbachia infection in individual mites was determined by the presence of an amplification product of part of the fts $Z$ gene using a primer pair that was specific for Wolbachia (Holden et al., 1993) (primer 1: 5'-gAT CCg TAT gCC gAT TgC AgA gCT Tg-3'; and primer 2: 5'-AAT TCg CCA TgA gTA TTC ACT Tgg CT-3').

Individual females were collected and crushed in $50 \mu \mathrm{L}$ sterile 5 per cent Chelex solution (weight: volume $=$ Chelex resin: $\mathrm{ddH}_{2} \mathrm{O}$ ) and $1 \mu \mathrm{L}$ filter-sterilized proteinase- $\mathrm{K}(20 \mathrm{mg} / \mathrm{mL})$. The solution was vortexed for $10 \mathrm{~s}$ and incubated at $37^{\circ} \mathrm{C}$ for $30 \mathrm{~min}$, vortexed again and centrifuged $(15000 \mathrm{~g} 2 \mathrm{~min}$ to pellet tissue and Chelex, followed by incubation at $96^{\circ} \mathrm{C}$ and centrifugation $(15000 \mathrm{~g} 1 \mathrm{~min})$. Samples were tested for Wolbachia in the PCR assay immediately after the DNA isolation.

Wolbachia fts $Z$ DNA was amplified in a $25 \mu \mathrm{L}$ PCR reaction volume $(10 \mu \mathrm{L}$ sample DNA, $2.5 \mu \mathrm{L}$ $10 \times$ buffer; $0.2 \mu \mathrm{L}$ nucleotide mix [10 mM each]; 0.3 $\mu \mathrm{L} 20 \mathrm{~mm}$ of each primer; $0.1 \mu \mathrm{L}$ superTaq; and 11.4 $\mu \mathrm{L} \mathrm{ddH}_{2} \mathrm{O}$ ). The PCR master mix was prepared in one batch and then added to each DNA sample. PCR was run on a Hybaid thermal cycler under the following cycle conditions: one cycle $\left(1 \mathrm{~min}\right.$ at $94^{\circ} \mathrm{C}$, $1 \mathrm{~min}$ at $55^{\circ} \mathrm{C}, 3 \mathrm{~min}$ at $72^{\circ} \mathrm{C}$ ) followed by 35 cycles $\left(15 \mathrm{~s}\right.$ at $94^{\circ} \mathrm{C}, 1 \mathrm{~min}$ at $55^{\circ} \mathrm{C}, 3 \mathrm{~min}$ at $\left.72^{\circ} \mathrm{C}\right)$. After PCR $4 \mu \mathrm{L}$ of amplified reaction product was run on a 0.7 per cent agarose gel stained with ethidium bromide to determine presence and size of amplified DNA.

\section{Antibiotic treatment of spider mites}

Female spider mites infected with Wolbachia were collected as (virgin) teleiochrysalides and upon emergence placed in a feeding arena. This arena consisted of two rectangular pieces (width $\times$ length$\times$ height $=5 \times 10 \times 0.5 \mathrm{~cm}$ ) of perspex with a $4 \mathrm{~cm}$ diameter hole in the middle. Parafilm was stretched out over the hole of one of the perspex pieces and a few droplets of 1 per cent glucose solution (with or without 0.1 per cent w/v tetracycline) were placed on top of the parafilm above the hole. Another piece of parafilm was stretched out covering the solution. The second piece of perspex was placed on top, enclosing the solution between the two layers of parafilm and the edge of the hole. The resulting chamber was closed off with a piece of glass.
Females were placed in the chamber between the parafilm/sucrose sandwich floor and the glass roof. Females were observed to pierce the parafilm with their stylets and feed on the solution underneath. This was evident from the peristaltic movement of their intestines. They were allowed to feed on the solution for $24 \mathrm{~h}$. After treatment, females were transferred to fresh bean leaves and allowed to lay eggs. Subsequent offspring were subjected to the same treatment as their mothers. This procedure was repeated for three generations. In the third generation, 30 treated females were individually placed on bean leaf discs, diameter $24 \mathrm{~mm}$, and allowed to lay eggs for 4 days and removed on day 5 for PCR assay. All females tested negative for Wolbachia in the PCR assay and their offspring were mixed together and used to start an uninfected lineage. The uninfected lineage has been maintained without further antibiotic treatment.

\section{Effect of Wolbachia on reproduction of the spider mite}

The effects of Wolbachia infection on host reproduction in the spider mite were established by combining infected and uninfected mites. Males and females were collected and separated as teleiochrysalides (the last resting stage before the adult reproductive phase). Upon emergence, single-pair matings were set up in all possible combinations of infected and uninfected individuals on bean leaf discs (diameter $24 \mathrm{~mm}$ ). After $24 \mathrm{~h}$ males were removed and females were transferred daily for 6 days to fresh bean leaf discs. On day 7 females were collected and individually tested in PCR assay for presence of Wolbachia. Number of eggs, subsequent offspring number and sex ratio were scored per day per female. A one-way analysis of variance (ANOVA statistical package, STATGRAPHics 6.0) was performed for each trait (number of sons, daughters, dead, clutch size, sex ratio and mortality) separately to determine if there was heterogeneity among different crosses with respect to each trait. If heterogeneity was significant, a Fisher's Least Significant Difference test (LSD) was carried out to determine which crosses were different (Sokal \& Rohlf, 1995). Sex ratios and percentage mortality were arcsine transformed prior to ANOVA analysis.

\section{Results}

Both tetranychid species harbour Wolbachia based on fts $Z$ PCR assay, consistent with earlier reports (Breeuwer \& Jacobs, 1996). PCR assays on indivi- 
dual mites collected at different times were always positive, proving the reliability of this assay and showing that the strain is fixed for the infection. To test whether Wolbachia can alter crossability in mites, infected and uninfected individuals were crossed in the four possible combinations in single pair matings and allowed to lay eggs. After 6 days of oviposition, all females from the infected strain were shown to be positive in the PCR assay, whereas all the females from the uninfected lineage tested negative. This confirmed that infection was fixed in the infected strain and still completely absent in the uninfected strain. It should be noted that, prior to the experiment, the cured strain had been without antibiotics for two generations and tested negative for Wolbachia in the PCR assay.

Females that did not produce more than 10 eggs over the 6 day oviposition period were discarded from the analysis. These females were either sterile or entered reproductive diapause (their body colour changed to orange, which is characteristic of reproductive diapause in spider mites). Females that died before Day 4 were also excluded. Fortunately, most sterile females were also the ones that died within four days; a few were damaged during initial daily transfers.

The results of crosses between infected and uninfected mites are shown in Tables 1 and 2 for $T$. urticae $(\mathrm{Tu})$ and $T$. turkestani $(\mathrm{Tt})$, respectively. Clutch sizes were significantly different, but crosses among infected $(\mathrm{I} \times \mathrm{I})$ and crosses among cured individuals $(\mathrm{U} \times \mathrm{U})$ were comparable. This shows that curing itself does not affect fertility of females. Similar to other examples of unidirectional incompatibility, the cross between cured females and infected males was different from all other crosses. Percentage offspring mortality was significantly higher (Tu: $\quad F_{3,147}=29.615, \quad P<0.0001 ; \quad \mathrm{Tt}$ : $\left.F_{3,43}=208.63, P<0.0001\right)$ compared to intrastrain crosses and the reciprocal cross between infected females and uninfected males. Mortality was manifested as failure of eggs to hatch similar to Wolbachia-induced incompatibility in diploid species such as Drosophila and Culex. This result was unexpected. Because spider mites are haplodiploid, incompatibility was expected to have the same effect as in other haplodiploids such as the wasp Nasonia, namely production of all male or male-biased offspring and

Table 1 Mean \pm SE offspring production (number of sons, daughters, dead mites and clutch size), sex ratio (proportion females) and percentage mortality produced in crosses (female $\times$ male) between infected (I) and uninfected (U) lineages of a Tetranychus urticae tomato strain. $N$ is number of replicate crosses

\begin{tabular}{|c|c|c|c|c|c|c|c|}
\hline Cross & Sons & Daughters & Dead & Clutch size & Sex ratio & Per cent mortality & $N$ \\
\hline $1 \times 1$ & $25.7 \pm 3.3^{\mathrm{a}}$ & $21.5 \pm 3.5^{\mathrm{a}}$ & $5.6 \pm 0.5^{\mathrm{a}}$ & $52.8 \pm 2.1^{\mathrm{a}}$ & $44 \pm 7^{\mathrm{a}, \mathrm{b}}$ & $11 \pm 1^{\mathrm{a}}$ & 31 \\
\hline $\mathrm{I} \times \mathrm{U}$ & $21.2 \pm 2.7^{\mathrm{a}}$ & $21.3 \pm 3.2^{\mathrm{a}}$ & $6.1 \pm 0.7^{\mathrm{a}}$ & $48.6 \pm 2.8^{\mathrm{a}, \mathrm{b}}$ & $47 \pm 6^{a, b}$ & $13 \pm 2^{a}$ & 37 \\
\hline $\mathrm{U} \times \mathrm{I}$ & $19.7 \pm 1.9^{\mathrm{a}}$ & $7.6 \pm 1.2^{\mathrm{b}}$ & $17.1 \pm 1.5^{b}$ & $44.4 \pm 1.9^{\mathrm{b}}$ & $30 \pm 4^{\mathrm{b}}$ & $39+3^{b}$ & 43 \\
\hline $\mathrm{U} \times \mathrm{U}$ & $24.0 \pm 2.7^{\mathrm{a}}$ & $22.8 \pm 2.7^{\mathrm{a}}$ & $7.9 \pm 0.9^{\mathrm{a}}$ & $54.7 \pm 2.2^{\mathrm{a}}$ & $48 \pm 5^{a}$ & $15 \pm 2^{a}$ & 40 \\
\hline
\end{tabular}

One-way ANOVAS were performed separately for each trait (column), with cross as factor. Comparisons within a column marked with the same superscript ( $a$ or $b)$ are not significantly different $(P<0.05)$ by a least significant difference (LSD) test (Sokal \& Rohlf, 1995).

Table 2 Mean \pm SE offspring production (number of sons, daughters, dead mites and clutch size), sex ratio (proportion females) and percentage mortality produced in crosses (female $\times$ male) between infected (I) and uninfected (U) lineages of a Tetranychus turkestani strain. $N$ is number of replicate crosses

\begin{tabular}{lcrrrrrr}
\hline Cross & Sons & Daughters & Dead & Clutch size & Sex ratio & Per cent mortality & $N$ \\
\hline $\mathrm{I} \times \mathrm{I}$ & $14.3 \pm 1.8^{\mathrm{a}}$ & $21.6 \pm 2.1^{\mathrm{a}}$ & $0.3 \pm 0.2^{\mathrm{a}}$ & $36.2 \pm 3.5^{\mathrm{a}}$ & $61 \pm 2^{\mathrm{a}}$ & $1 \pm 1^{\mathrm{a}}$ & 12 \\
$\mathrm{I} \times \mathrm{U}$ & $18.5 \pm 2.7^{\mathrm{a}} \mathrm{b}$ & $18.8 \pm 2.2^{\mathrm{a}}$ & $0.8 \pm 0.3^{\mathrm{a}}$ & $38.1 \pm 4.2^{\mathrm{a}}$ & $53 \pm 4^{\mathrm{b}}$ & $3 \pm 2^{\mathrm{a}}$ & 12 \\
$\mathrm{U} \times \mathrm{I}$ & $19.8 \pm 1.5^{\mathrm{b}}$ & $2.5 \pm 0.5^{\mathrm{b}}$ & $21.7 \pm 1.2^{\mathrm{b}}$ & $44.0 \pm 1.7^{\mathrm{a}}$ & $12 \pm 2^{\mathrm{c}}$ & $50 \pm 2^{\mathrm{b}}$ & 12 \\
$\mathrm{U} \times \mathrm{U}$ & $14.5 \pm 1.1^{\mathrm{a}, \mathrm{b}}$ & $23.7 \pm 1.9^{\mathrm{a}}$ & $1.6 \pm 0.6^{\mathrm{a}}$ & $39.8 \pm 2.5^{\mathrm{a}}$ & $62 \pm 3^{\mathrm{a}}$ & $4 \pm 1^{\mathrm{a}}$ & 11 \\
\hline
\end{tabular}

One-way ANOVAS were performed separately for each trait (column), with cross as factor. Comparisons within a column marked with the same superscript $(\mathrm{a}, \mathrm{b}$ or $\mathrm{c})$ are not significantly different $(P<0.05)$ by a least significant difference (LSD) test (Sokal \& Rohlf, 1995). 
typically with no or little mortality. However, the numbers of sons produced were not different between crosses (Tu: $F_{3,147}=1.070, P=0.3636$; Tt: $F_{3,43}=2.149, P=0.1080$ ), but the numbers of adult daughters produced in incompatible pairs were greatly reduced (Tu: $F_{3,147}=8.146, P<0.0001 ; \mathrm{Tt}$ : $\left.F_{3,43}=28.673, P<0.0001\right)$. The reduction in the number of adult daughters obviously coincides with the increased number of dead in the same cross between infected males and uninfected females. This suggests that mortality occurred only among fertilized eggs, which normally give rise to females, and not among unfertilized eggs, which develop into males. If the same mechanism is operating in spider mites as in insects, it is possible that paternal genome loss is incomplete in spider mites. Cytoplasmic incompatibility may then result in aneuploid zygotes which are inviable. In conclusion, the results clearly show that Wolbachia can cause cytoplasmic incompatibility in these spider mites.

\section{Discussion}

Wolbachia are widespread in insects. Recently, Breeuwer \& Jacobs (1996) reported on the widespread occurrence of Wolbachia in spider mites and predatory mites, which appears to parallel the situation in insects. Wolbachia-induced reproductive incompatibility has been postulated as a possible explanation for zygotic mortality (egg hatching failure) and male-biased sex ratios in crosses between geographical strains of the spider mite $T$. quercivorus (Gotoh et al., 1995) and in the predatory mite $M$. occidentalis (Hoy \& Cave, 1988). This is the first study that shows that Wolbachia are indeed involved in unidirectional cytoplasmic incompatibility in the spider mites T. urticae and T. turkestani.

Nothing is known about the cytological mechanism of cytoplasmic incompatibility in spider mites. It probably results in paternal genome loss similar to the mechanism in insects. However, paternal genome loss apparently does not result in haploidization of the egg and subsequent development into a (haploid) male, despite the fact that these spider mites are haplodiploid. This is in sharp contrast to cytoplasmic incompatibility in the haplodiploid parasitoid wasp Nasonia (Ryan \& Saul, 1968; Breeuwer \& Werren, 1990; Reed \& Werren, 1995), in which paternal genome loss typically results in complete haploidization of fertilized eggs and subsequent development into (haploid) males. There are two possibilities that may explain the zygotic mortality and absence of haploidization in spider mites: low bacterial infection levels and their holokinetic chromosome structure. Breeuwer \& Werren (1993) showed that embryo mortality in partially incompatible crosses in Nasonia was correlated with lowered bacterial densities during male development. Subsequent incompatible crosses involving such males may not always result in complete paternal chromosome elimination (Reed \& Werren, 1995) and produce inviable, aneuploid embryos or mosaic embryos with diploid and haploid nuclei.

Chromosomes of spider mites are holokinetic and have a diffuse centromere; microtubules can attach anywhere on the chromosome (Tempelaar, 1980). In Nasonia, Ryan et al. (1987) suggested that survival and stable transmission of chromosome pieces depends upon the presence of a centromere. All holokinetic chromosome fragments are in principle able to attach to microtubules and be pulled into the newly formed nuclei. This chromosome structure of spider mites may increase the probability that nuclei become aneuploid upon cytoplasmic incompatibility and prevent haploidization of fertilized eggs. Radiation studies in spider mites showed that pieces of fragmented chromosomes were incorporated into the nucleus, but were unstably transmitted and frequently lost in successive mitotic divisions. This also resulted in increased mortality compared to controls (Tempelaar, 1980).

I expect the occurrence of Wolbachia-induced cytoplasmic incompatibility in mites to parallel the situation in insects. The nonreciprocal zygotic mortality in crosses between geographical populations of the predatory mite $M$. occidentalis appears to be correlated with the cytological and molecular detection of Wolbachia (Hess \& Hoy, 1982; Johanowicz \& Hoy, 1996). Although the procedure suggested by Werren \& Jaenike (1995) to demonstrate unequivocally that incompatibility is caused by microorganisms has yet to be carried out, Wolbachia are likely to be involved in geographical incompatibilities in this predatory mite. Gotoh et al. (1995) reported unidirectional incompatibility between northern and southern populations of T. quercivorus in Japan. Based on antibiotic and heat treatment experiments, they dismissed the possibility that microorganisms were involved. However, there are several reasons why these treatments may not have altered incompatibility. Unidirectional incompatibility is typically observed between uninfected females and infected males. Thus, if microorganisms are involved, the northern Sapporo strain is expected to be uninfected and the southern Tsukuba strain to be infected, because Sapporo females are incompatible with Tsukuba males. Therefore, antibiotic and heat treatment of the 'uninfected' Sapporo females is not 
expected to alter incompatibility with 'infected' Tsukuba males. Treatment of infected males during development could in principle render them uninfected at the time of mating and compatible with uninfected females. However, treatment of infected males may not be very effective, because compatibility type of males (their sperm) is probably determined very early in male development (Breeuwer \& Werren, 1993). This may explain why after antibiotic treatment of 'infected' Tsukuba males, they remained incompatible with 'uninfected' Sapporo females.

However, there are other explanations for the afore-cited reproductive incompatibilities in mites. For example: (i) any prezygotic isolating mechanism that results in limited sperm availability may result in a high proportion of unfertilized eggs. Similar to cytoplasmic incompatibility, such eggs will develop into males in haplodiploids and give rise to malebiased sex ratios, but lead to zygotic mortality in diploids; and (ii) hybrid (female) mortality may be caused by nuclear-nuclear or nuclear-cytoplasmic interactions (Fry, 1989; Gotoh et al., 1995). Finally, presence of Wolbachia is no guarantee that they are the cause of cytoplasmic incompatibility, because some Wolbachia are incapable of inducing cytoplasmic incompatibility in their host (Giordano et al., 1995; Turelli \& Hoffmann, 1995).

Wolbachia have been suggested to play a role in speciation (Laven, 1967; Legrand et al., 1986; Breeuwer \& Werren, 1990; Coyne, 1992). The two-spotted spider mite occurs on a wide range of (biochemically) different host plants. Furthermore, this mite is able to colonize and adapt rapidly to new host plants (Gould, 1979; Fry, 1989). Gotoh et al. (1993) found evidence for host race formation based on host-plant and mating preference and host-plantassociated fitness trade-offs between mites collected from cucumber and tomato plants in greenhouses in The Netherlands. In addition, they showed that some postzygotic isolating mechanism is operating between these two strains, resulting in aberrant $F_{1}$ sex ratios and increased $F_{2}$ male mortality compared to intrastrain crosses. Crossing experiments in combination with antibiotic treatment and molecular detection of Wolbachia will easily distinguish between these hypotheses and Wolbachia-induced cytoplasmic incompatibility.

\section{Acknowledgements}

I would like to thank Gerrit Jacobs and Filipa Vala for their help with the experiments. This research has been funded by the Royal Netherlands Academy of Arts and Sciences.

\section{References}

BOER, R. DE AND VEERMAN, A. 1983. A case of hybrid inviability in the two-spotted spider mite, Tetranychus urticae. Entomologia exp. appl., 34, 127-128.

BREEUWER, J. A. J. AND JACOBS, G, 1996. Wolbachia: intracellular manipulators of mite reproduction. Exp. Appl. Acarol., 20, 421-434.

BREEUWER, J. A. J. AND WERREN, J. H. 1990. Microorganisms associated with chromosome destruction and reproductive isolation between two insect species. Nature, 346, 558-560.

BREeUWER, J. A. J. AND Werren, J. H. 1993. Cytoplasmic incompatibility and bacterial density in Nasonia vitripennis. Genetics, 135, 565-574.

breeuWer, J. A. J., Stouthamer, R., Barns, s. M., PelletIER, D. A., Weisburg, W. G. AND WERrEN, J. H. 1992. Phylogeny of cytoplasmic incompatibility microorganisms in the parasitoid wasp genus Nasonia (Hymenoptera: Pteromalidae) based on $16 \mathrm{~S}$ ribosomal DNA sequences. Insect Mol. Biol., 1, 25-36.

CAllaini, G., Riparbelli, M. G. AND dallai, R. 1994. The distribution of cytoplasmic bacteria in the early Drosophila embryo is mediated by astral microtubules. J. Cell Sci., 107, 673-682.

COYne, J. A. 1992. Genetics and speciation. Nature, 355, 511-515.

DILLON, L. S. 1958. Reproductive isolation among certain spider mites of the Tetranychus urticae complex with preliminary notes. Ann. Entomol. Soc. Am., 51, $441-448$.

FRY, J. D. 1989. Nuclear-nuclear and nuclear-cytoplasmic interactions contribute to the reproductive incompatibility between two strains of the two-spotted spider mite. Entomologia exp. appl., 50, 97-100.

GIORDANO, R., O'NEILL, S. O. AND ROBERTSON, H. M. 1995. Wolbachia infections and the expression of cytoplasmic incompatibility in Drosophila sechellia and D. mauritiana. Genetics, 140, 1307-1317.

GOTOH, T. AND NOGUCHI, O. 1990. Developmental success and reproductive incompatibility among populations of the European red mite, Panonychus ulmi (Acari: Tetranychidae). Exp. Appl. Acarol., 10, 157-165.

GOTOH, T., BRUIN, J., SABELIS, M. W. AND MENKEN, S. B. J. 1993. Host race formation in Tetranychus urticae: genetic differentiation, host plant preference, and mate choice in a tomato and a cucumber strain. Entomologia exp. appl., 68, 171-178.

GOTOH, T., OKU, H., MORIYA, K. AND ODAWARA, M. 1995. Nucleus-cytoplasm interactions causing reproductive incompatibility between two populations of Tetranychus quercivorus Ehara et Gotoh (Acari: Tetranychidae). Heredity, 74, 405-414.

GOULD, F. 1979. Rapid host range evolution in a population of the phytophagous mite Tetranychus urticae Koch. Evolution, 33, 791-802. 
GUTIERREZ, J. AND ZON, A. Q. VAN 1973. A comparative study of several strains of the Tetranychus neocaledonicus complex and sterilization tests of males by X-rays. Entomologia exp. appl., 16, 123-134.

HESS, R. T. AND HOY, M. A. 1982. Microorganisms associated with the spider mite predator Metaseiulus (= Typhlodromus) occidentalis: electron microscope observations. J. Invert. Pathol., 40, 98-106.

HOFFMANN, A. A. AND TURELLI, M. 1988. Unidirectional incompatibility between populations of Drosophila simulans: inheritance, geographic variation and fitness effects. Genetics, 119, 435-444.

HOLdEN, P. E., BROOKFIELD, J. F. Y. AND JONES, P. 1993. Cloning and characterization of an fts $Z$ homologue from a bacterial symbiont of Drosophila melanogaster. Mol. Gen. Genet., 240, 213-220.

HOY, M. A. AND CAVE, F. E. 1988. Premating and postmating isolation among populations of Metaseiulus occidentalis (Nesbitt) (Acarina: Phytoseiidae). Hilgardia, 56, $1-20$.

JOHANOWIZC, D. L. AND HOY, M. A. 1996. Wolbachia in a predator-prey system: 16S ribosomal DNA analysis of two phytoseiids (Acari: Phytoseiidae) and their prey (Acari: Tetranychidae). Ann. Entomol. Soc. Am., 89, 435-441.

JOST, E. 1970. Untersuchungen zur Kreuzungssterilität im Culex pipiens Komplex. Wilhelm Roux Arch. Entwickl. Org., 166, 173-188.

LAVEN, H. 1967. Speciation and evolution in Culex pipiens. In: Wright, J. W. and Pal, R. (eds) Genetics of Insect Vectors of Disease, pp. 251-275. Elsevier, Amsterdam.

LEGRAND, J. J., JUCHAULT, P., MORAGA, D. AND LEGRANDHAMELIN, E. 1986. Microorganismes symbiotiques et spéciation. Bull. Soc. Zool. Fr., 111, 135-147.

o'NEILL, S. L. AND KARR, T. L. 1990. Bidirectional incompatibility between conspecific populations of Drosophila simulans. Nature, 348, 178-180.

O'NEILL, S. L., GIORDANO, R., COI_BERT, A. M. E., KARR, T. L. AND ROBERTSON, H. M. 1992. 16S rRNA phylogenetic analysis of the bacterial endosymbionts associated with cytoplasmic incompatibility in insects. Proc. Natl. Acad. Sci, U.S.A., 89, 2699-2702.

OSAKABE, M. 1993. Divergence of the northern and southwestern populations of Panonychus mori (Yokoyama) (Acari: Tetranychidae) in Japan in host range and reproductive compatibility. Appl. Ent. Zool., 28, 189-197.

REED, K. AND WERREN, J. H. 1995. Induction of paternal genome loss by the paternal sex ratio chromosome and cytoplasmic incompatibility bacteria (Wolbachia): a comparison of early embryonic events. Mol. Reprod. Dev., 40, 408-418.

RICHARDSON, P. M., holmes, W. P. AND SAul, G. B., I1. 1987.
The effects of tetracycline on nonreciprocal incompatibility in Mormoniella [ = Nasonia] vitripennis. J. Invert. Pathol., 50, 176-183.

RIGAUD, T., SOUTY-GROSSET, C., RAIMOND, R., MOCQUARD, J. AND JuCHAUlT, P. 1991. Feminizing endocytobiosis in the terrestrial crustacean Armadillidium vulgare Latr. (Isopoda): recent acquisitions. Endocytobiosis Cell. Res., 7, 259-273.

Rousset, F., Bouchon, D., PINTUREAu, B., JUCHAUlt, P. AND SOlignaC, M. 1992. Wolbachia endosymbionts responsible for various alterations of sexuality in arthropods. Proc. R. Soc. B, 250, 91-98.

RYAN, S. L. AND SAUL, G. B., II. 1968. Post-fertilization effect of incompatibility factors in Mormoniella. Mol. Gen. Genet., 103, 29-36.

RYAN, S. L., SAul, G. B., II AND CONNER, G. w. 1987. Separation of factors containing $\mathrm{R}$-locus genes in Mormoniella stocks derived from aberrant segregation following incompatible crosses. J. Hered, 78, 273-275.

SOKAL, R. R. AND ROHLF, F. J. 1995. Biometry, 3rd edn. W. H. Freeman and Company, New York.

SOlOGIC, H. D. AND RODRIGUEZ, J. G. 1971. Microorganisms associated with the two-spotted spider mite Tetranychus urticae. J. Invert. Pathol., 17, 48-52.

STOUTHAMER, R., BREEUWER, J. A. J., LUCK, R. F. AND WERREN, J. H. 1993. Molecular identification of microorganisms associated with parthenogenesis. Nature, 361, 66-68.

TEMPELAAR, M. J. 1980. Radiobiological and Structural Studies of the Holokinetic Chromosomes of the Spider Mite Tetranychus urticae Koch. Ph.D. Thesis, University of Groningen, The Netherlands.

TSAGKarakou, A., Gulllemaud, T., Rousset, F. AND NAVAJAS, M. 1996. Molecular identification of a Wolbachia endosymbiont in a Tetranychus urticae strain (Acari: Tetranychidae). Insect Mol. Biol., 5, 217-221.

TUREll1, M. AND hofFMANN, A. A. 1995. Cytoplasmic incompatibility in Drosophila simulans: dynamics and parameter estimates from natural populations. Genetics, 140, 1319-1338.

WERREN, J. H. AND JAENIKE, J. 1995. Wolbachia and cytoplasmic incompatibility in mycophagous Drosophila and their relatives. Heredity, 75, 320-326.

WERREN, J. H., WINDSOR, D. AND GUO, L. R. 1995a. Distribution of Wolbachia among neotropical arthropods. Proc. R. Soc. Lond. B, 262, 197-204.

WERREN, J. H., ZHANG, w. AND GUO, L. R. 1995b. Evolution and phylogeny of Wolbachia: reproductive parasites of arthropods. Proc. R. Soc. B, 261, 55-71.

YOUNG, S. S. Y., WRENSCH, D. L. AND KONGCHUESIN, M. 1985. Geographic variations and combining abilities in the two-spotted spider mite, Tetranychus urticae. Entomologia exp. appl., 39, 109-113. 